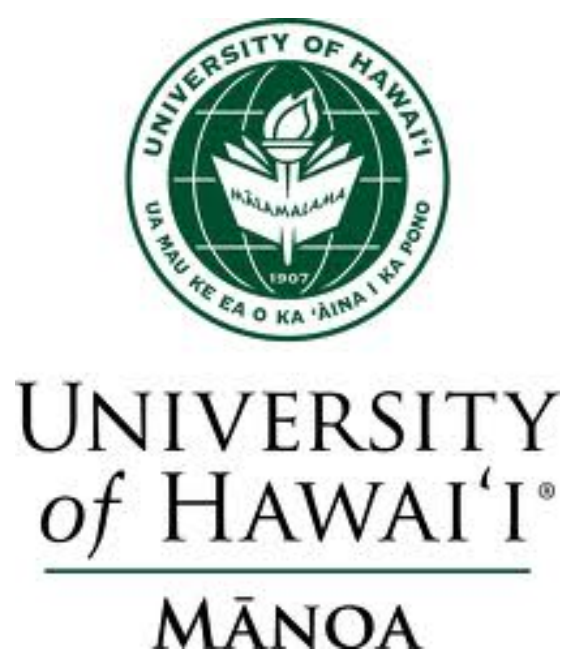

University of Hawai $i$ at Mānoa Department of Economics Working Paper Series

Saunders Hall 542, 2424 Maile Way, Honolulu, HI 96822

Phone: (808) $956-8496$ www.economics.hawaii.edu

Working Paper No. 12-14

Unemployment and Mortality: Evidence from the PSID

By

Timothy J. Halliday

July 2012 


\title{
Unemployment and Mortality: Evidence from the
}

\section{PSID}

\author{
Timothy J. Halliday* \\ University of Hawai'a at Manoa and IZA
}

July 31, 2012

\begin{abstract}
In this paper, we use the death file from the Panel Study of Income Dynamics to investigate the relationship between county-level unemployment rates and mortality risk. After partialling out important confounding factors including baseline health status as well as state, industry and occupation fixed effects, we show that poor local labor market conditions are associated with higher mortality risk for working-aged men. There is little to no such relationship for people with weaker labor force attachments such as women or
\end{abstract}

${ }^{*}$ I would like to thank Doug Miller for useful comments. Address: 2424 Maile Way; Saunders Hall 533; Honolulu, HI 96822. Tele: (808) 956 - 8615. Email: halliday@hawaii.edu. All errors are my own. 
the elderly. Our results contribute to a growing body of work that suggests that poor economic conditions pose health risks and illustrate an important contrast with studies based on aggregate data. The latter underscores the need to arrive at a better understanding of the aggregation mechanism linking the micro and macro studies.

Key words: Recessions, Mortality, Health, Aggregation

JEL: I0, I12, J1

\section{Introduction}

Recent work has used micro-data to establish a robust relationship between job displacement and adverse health outcomes. For example, Sullivan and von Wachter (2009) use administrative data from Pennsylvania and show that job displacement is strongly associated with increased mortality risk. In a similar paper, Strully (2009) uses the Panel Study of Income Dynamics (PSID) and shows that job displacement is strongly associated with increased morbidity. Overall, these papers suggest that there are negative health consequences to losing one's job.

In this paper, we add to this growing literature by investigating the relationship between county-level unemployment rates and mortality using the PSID's mortality file. Rather than focus on individual job displacements, we focus on county-level 
unemployment rates. One advantage of doing so is that individuals have less discretion over local employment conditions than they have over their own employment status. Another advantage is that it provides a specification that is similar to some of the studies that use aggregate data on unemployment and mortality such as Ruhm (2000), Huff-Stevens, Miller, Page, Huff-Stevens, and Filipski (2009), and Huff-Stevens, Miller, Page, and Filipski (2011) albeit with micro-data. In fact, if one were to take expectations of our specification over American states then it would be the same as the specifications used in aggregate studies.

Similar to previous studies, we show that higher unemployment is associated with higher mortality risk. This relationship primarily holds for working-aged men and is robust to the inclusion of state, industry and occupation dummies as well as baseline health status. It is substantially attenuated for working-aged women and nonexistent for people over 60 . Overall, it is strongest for people with the largest labor force attachment. This stands in stark contrast to studies that use aggregate data that find a significant and negative relationship between unemployment and mortality for the very young and the very old who should have no attachment to the labor market. Also, note that if our results were being driven by counties with high unemployment being inhabited by less healthy people then we would expect to see this relationship for everybody not just working-aged men. This alleviates 
concerns that this relationship is spurious. Overall, the conclusions of the previous studies that use micro-data are supported once we adopt our alternative approach. However, the similarity of our variable definitions and the immense divergence in the results between our study and studies that employ macro-data suggests the presence of an aggregation bias in the latter. Future work should investigate this.

The balance of this paper is organized as follows. In the next section, we discuss our data. After that, we discuss our results. Finally, we conclude and offer some insights into how measurement issues can possibly explain the divergence between the results at the micro and the macro levels.

\section{Data}

We employ data on people between the ages of 25 and 80 (inclusive) from the PSID survey years 1984 to 1993 . Our sample starts at 1984 because the Self-Reported Health Status (SRHS) question is not available prior to that year. The sample ends at 1993 because county level unemployment rates are not available beyond then. The covariates that we use are county level unemployment rates, SRHS which is a categorical variable between 1 (excellent) and 5 (poor) that respondents use to rate their own health, age, educational attainment, gender, and race. Summary 
statistics are reported in Table 1. Additional detail concerning how the sample was constructed can be found in the Appendix.

Information on mortality comes from the PSID's mortality file which contains the death years of any PSID members who died on or before 2005 as well as the primary cause of their death. The cause of death was coded according to the International Classification of Death (ICD). For deaths that occurred prior to 1999, the ICD9 was used. After 1999, the ICD10 was used.

A total of 1016 individuals from our sample had died prior to 2005, although we do not know the year of death for 8 of these people. The two biggest broadly defined causes of death in our data were diseases of the circulatory system, which correspond to ICD9 codes 390 to 459 or ICD10 codes beginning in I and neoplasms, which correspond to ICD9 codes 140 to 239 or ICD10 codes beginning in C. There were 364 deaths from circulatory diseases, which includes heart attacks, and 229 deaths from cancer in our sample. Because these causes of death are very frequent, we will consider them separately in our analysis. Other causes of death are too infrequent to consider on their own. 


\section{Methods}

To shed light on the relationship between unemployment and mortality, we consider the following model

$$
P\left(d_{i t}^{j}=1 \mid u_{i t}, X_{i t}\right)=\Phi\left(\alpha^{j}+u_{i t} \beta^{j}+X_{i t}^{\prime} \theta^{j}\right) \text { for } j=1, \ldots, 10
$$

where $u_{i t}$ is the unemployment rate in the individual's county of residence and $X_{i t}$ is a column vector that includes dummies for SRHS being equal to one, two, three, or four; a quadratic function in age; dummy variables for educational attainment; and a dummy variable for being Caucasian. In some robustness checks, we also include fixed effects for state, year, industry and occupation. The function $\Phi($.$) denotes the$ normal CDF and the subscript $t$ corresponds to the survey year. The dependent variable is an indicator that is turned on if the individual has died within $j$ years of the survey year. So, $d_{i t}^{5}=1$ if the individual has died within 5 years of survey year t. As in Meghir and Pistaferri (2004), we adjust all standard errors for clustering on individuals. Adjusting standard errors for correlations within individuals is standard procedure in the PSID.

The strategy that we use to identify the effect of unemployment on mortality is essentially selection-on-observables, but without a binary treatment variable. This is 
somewhat of a common procedure in the literature on unemployment and health (e.g. Browning, Dano, and Heinesen (2006), Strully (2009), and Sullivan and von Wachter (2009)). We are careful to control for important confounding factors including health status, education, age and race in a flexible manner. In addition, in some robustness checks, we control for state, year, industry and occupation fixed effects. We focus on county level unemployment rates rather than indicators for being unemployed as has been done by other studies because individuals have far less discretion over local macroeconomic conditions than their personal employment status.

The approach that we and others in this literature adopt hinges on our ability to completely control for all confounding variables. As such, there may be some bias in our estimates. To help us to better establish if any effects that we find are real, we will estimate the model on different subsamples with varying degrees of attachment to the labor market. The groups are men and women 60 and under and men and women over 60. Clearly, working age men will have the largest attachment to the labor market and if there truly are effects running from unemployment to health, the estimates should be the largest for them. On the other hand, both men and women over 60 have the weakest attachment to the labor market and so we should expect to see no effects for them. In other words, if the county level unemployment rates are mostly picking up omitted variables then we would expect to see a significant 
relationship between unemployment and mortality for people who have weak labor market attachments.

\section{Empirical Results}

\subsection{Core Results}

In Table 2, we report the marginal effects of unemployment on mortality by any cause. For men ages 60 and under, we see that higher unemployment rates at the county level predict higher mortality once we partial out important confounding variables including controls for baseline health status. For this demographic group, there is a statistically significant effect of high unemployment on dying within between one and ten years of baseline (i.e. the year in which the unemployment rates were measured). Of note is that the marginal effects increase monotonically as we look at mortality further out from the baseline. In particular, we see that a one percentage point increase in unemployment is associated with an increased probability of dying within ten years of baseline of 0.163 percentage points.

In the same table, when we look at people with a weaker attachment to the labor market such as women and people older than 60, we see a different picture. For working age women, we see a substantially attenuated relationship between unem- 
ployment and mortality. Most of the estimates are not significant at conventional levels. For people older than 60, there is no such relationship. The bottom line is that we see very significant effects for working age men for whom labor force attachment is the strongest, much smaller effects for working age women for whom attachment is somewhat weaker, and no effects for the elderly for whom there is virtually no attachment. This stands in stark contrast to results in Huff-Stevens, Miller, Page, Huff-Stevens, and Filipski (2009) who use aggregate data and show that there is a significant negative relationship between unemployment and mortality rates at the state level for people who have a weak labor force attachment, particularly the elderly.

\subsection{Robustness Checks}

We now include a comprehensive set of robustness checks of the results in Table 2. In particular, we investigate the robustness of our results to state and year fixed effects as well as state-specific time trends. It is important to point out that inclusion of these additional controls greatly reduces the variation in the county level unemployment rates. To see illustrate this, we present Table 3 in which we report the $R^{2}$ of a regression of county level unemployment rates onto state and year fixed

effects. We see that, even with only state fixed effects, the $R^{2}$ is 0.2753 . Once we 
include either year fixed effects or state-specific time trends, the $R^{2}$ jumps to over $33 \%$. Controlling for state and temporal variation eliminates about one-third of the variation in the unemployment rates, so this should be viewed as a more stringent test. This is certainly desirable in the sense that it goes a long way towards eliminating confounding variables, but it is less desirable in that it may expunge variation in the county-level unemployment rate that is truly exogenous. This may be especially problematic given that the variation in our dependent variables is not terribly high since only about $1 \%$ of our observations died within one year of the survey and only about $9 \%$ died within 10 years of the survey. Finally, in addition to adjusting for state and temporal variation, we also include additional results in which we control for 3-digit industry and occupation codes. ${ }^{1}$

We report the results in Tables 4 and 5, respectively. For men, when we include state fixed effects only, we see that the point-estimates are basically unchanged from the first column of Table 2. In column (2), we include year fixed-effects and the results are still very similar to the previous table. In column (3), we include statespecific time trends. This does attenuate the point-estimates, particularly for dying within four years of baseline. However, beyond four years, we still see that all of the

\footnotetext{
${ }^{1}$ In the PSID, the survey enumerator asks the respondent if they have an occupation. This is then followed by asking the respondent what industry their occupation is in. If the individual is not presently "working for money" then occupation or industry is coded as zero. We include these individuals (with an additional dummy for zero) in all of the estimations so as not to induce any selectivity biases.
} 
estimates are significant at the $10 \%$ level or under. Finally, the results are robust to controlling for industry and occupation fixed effects and, if anything some of the estimates appear to increase in magnitude. Finally, turning to working-aged women, we see that adjusting for a variety of fixed effects does not alter the conclusions of the previous table.

\subsection{Results by Cause of Death}

In Tables 6 and 7, we look at the relationship between unemployment and mortality for two common causes of death: cancer and diseases of the circulatory system which includes heart attacks. The basic patterns of the previous table are borne out here, although the marginal effects are smaller. Specifically, we see effects for working age men and no effects for the other demographic groups. Interestingly, we see that the marginal effects when looking at death by neoplasm are small and insignificant for deaths within five years of baseline, but are significant for deaths that occur over five years after baseline. This may reflect that cancers can be slow growing and may take many years to manifest. In contrast, while we do see the same increasing pattern for diseases of the circulatory system, the effects can be seen within one year of baseline, whereas with neoplasms they cannot. 


\section{Conclusions}

In this paper, we employed mortality information from the PSID to establish a robust positive association between unemployment as proxied by county level unemployment rates and mortality. This relationship was the strongest for working-aged men. There was weak evidence of a relationship for working-aged women and no evidence for people older than 60. Hence, the results hold for people with the strongest attachment to the labor market. These results compliment findings in

Halliday (2012) that earnings shocks have substantial adverse effects on self-rated health for working-aged men but no effects for working-aged women.

Our findings along with Strully (2009) and Sullivan and von Wachter (2009) stand in stark contrast to results based on aggregate data such as Ruhm (2000) where there is a negative relationship between unemployment and mortality. Notably, HuffStevens, Miller, Page, Huff-Stevens, and Filipski (2009) show that this relationship holds for the very old and the very young suggesting that the mechanism for the result has to be something that is unrelated to job loss. More recent work by Huff-Stevens, Miller, Page, and Filipski (2011) suggests that these results are the consequences of increases in vehicular accidents and decreases in the quality of medical care for the elderly during boom times. 
It is instructive to consider how our specification relates to the macro work. To fix ideas, we write a linear model at the individual level

$$
d_{i s t}^{1}=\alpha+\beta u_{s t}+\delta_{s}+\varepsilon_{i s t}
$$

where the $s$ subscript denotes states. For the sake of simplicity, we let $u_{s t}$ denote the state level unemployment rate. If we take expectations over states at a point-in-time, then we obtain

$$
d_{s t}^{1}=\alpha+\beta u_{s t}+\delta_{s}+\varepsilon_{s t}
$$

where we have adopted the notation that $z_{s t}=E\left[z_{i s t}\right]$. The model in equation (2) is the same as those that are estimated by Ruhm (2000) and others who investigate the relationship between unemployment rates and mortality at the state level while employing state fixed effects. If there are no issues with the aggregation, then estimates of $\beta$ using either model should be the same. If they are different this suggests that aggregation biases are present.

In our view, this is a topic worthy of future investigation. Importantly, moving from the micro model in equation (1) to the macro model in equation (2) necessitates an accurate measurement of $d_{s t}^{1}=E\left[d_{i s t}^{1}\right]$ which is the probability that an individual will die in a given state at a given time. If there are errors in this measurement 
that are correlated with $u_{s t}$ then this will cause estimates of $\beta$ in model (2) to be biased. The advantage of model (1) is that measurement of $d_{i s t}^{1}$ is trivial whereas the measurement of $d_{s t}^{1}$ is not. This idea that parameter estimates can differ depending on the level of aggregation has deep roots in economics (see Blundell and Stoker (2005) for a discussion).

We suspect that measurement errors might matter for two reasons. First, as pointed out by Blanchard and Katz (1992), local economic shocks are typically dealt with by large out-migrations. Second, measurement of mortality rates is particularly sensitive to their denominators which can change substantially because of migration. Future work should investigate the degree to which migration in response to business cycle fluctuations can explain this paradox.

One way that this could be done is to employ administrative data. Doing so would yield close to a census of individual deaths that could subsequently be aggregated to the state level. One could then estimate the models in equations (1) and (2) and see how the estimates of $\beta$ compare. This could not be credibly done with the PSID, however, since we only have 1000 deaths covering 50 states and 10 years yielding 2 deaths per state/year on average. Administrative data is needed. 


\section{Appendix: Sample Construction}

The sample construction in this paper mimics that of Halliday (2012) with the exception that we extend the sample to include people 80 or under, whereas Halliday (2012) uses people 60 or under. We begin with 20,338 individuals. Next, we dropped people with incomplete information on SRHS. This dropped the sample size to 20,222. Next, we dropped people whose first-differenced log earnings was smaller than -1 or greater than 5 which further dropped the sample size to 18,073 . While this paper is not concerned with earnings per se, we used this sample restriction to ensure that the two samples in both papers were comparable. Next, we further restricted the sample to people who were between ages 25 and 80 (inclusive). This brought the sample size to 16,840 . Next, we dropped individuals whose ages

declined by more than one year or increased by more than two years. After doing this, the sample size became 14,908. We then dropped people who were not in the sample continuously which dropped the sample size to 11,767. Finally, we kept only people who were in the panel for at least three years which brought the sample size to 7,282 . 


\section{References}

Blanchard, O., And L. Katz (1992): "Regional Evolutions," Brookings Papers on Economic Activity, (1), 1-61.

Blundell, R., And T. Stoker (2005): "Heterogeneity and Aggregation," Journal of Economic Literature, 43(2), 347-391.

Browning, M., A. Dano, and E. Heinesen (2006): "Job Displacement and Stress-Related Health Outcomes," Health Economics, 15(10), 1061-1075.

Halliday, T. (2012): "Earnings Growth and Movements in Self-Rated Health," IZA Working Paper.

Huff-Stevens, A., D. Miller, M. Page, and M. Filipski (2011): "The Best of Times, The Worst of Times: Understanding Procyclical Mortality," NBER Working Paper.

Huff-Stevens, A., D. Miller, M. Page, A. Huff-Stevens, and M. Filipski (2009): "Why are recessions good for your health?," American Economic Review, $99(2), 122-127$.

Meghir, C., And L. Pistaferri (2004): "Income Variance Dynamics and Heterogeneity," Econometrica, 72(1), 1-32. 
Ruhm, C. (2000): "Are Recssions Good for your Health?," Quarterly Journal of Economics, 115(2), 617-50.

Strully, K. (2009): "Job Loss and Health in the US Labor Market," Demography, 46(2), 221-246.

Sullivan, D., and T. von Wachter (2009): "Job Displacement and Mortality: An Analysis Using Administrative Data," Quarterly Journal of Economics, 124(3), $1265-1306$. 
Table 1: Descriptive Statistics

\begin{tabular}{lcc} 
& Men & Women \\
\hline \hline \multirow{2}{*}{ County Level Unemployment Rate } & 5.97 & 6.07 \\
& $(2.47)$ & $(2.45)$ \\
SRHS $=1$ & 0.28 & 0.19 \\
& $(0.45)$ & $(0.40)$ \\
SRHS $=2$ & 0.35 & 0.30 \\
& $(0.48)$ & $(0.46)$ \\
SRHS $=3$ & 0.25 & 0.30 \\
& $(0.43)$ & $(0.46)$ \\
SRHS $=4$ & 0.09 & 0.14 \\
& $(0.29)$ & $(0.35)$ \\
Age & 41.89 & 45.73 \\
& $(12.72)$ & $(15.08)$ \\
College Degree & 0.30 & 0.22 \\
& $(0.46)$ & $(15.08)$ \\
More than 12 Years of Schooling & 0.50 & 0.41 \\
& $(0.50)$ & $(0.50)$ \\
Caucasian & 0.72 & 0.65 \\
& $(0.45)$ & $(0.48)$ \\
\hline \hline$N$ & 3776 & 3506
\end{tabular}


Table 2: Mortality: Any Cause

\begin{tabular}{ccccc} 
Died & Men & Women & Men & Women \\
\hline \hline & 60 and Under & \multicolumn{2}{c}{ Over 60} \\
\hline \hline$\leq 1$ & 0.00026 & 0.00007 & -0.00301 & -0.00187 \\
& $(2.36)$ & $(0.82)$ & $(-1.33)$ & $(-1.41)$ \\
$\leq 2$ & 0.00041 & 0.00005 & -0.00265 & -0.00081 \\
& $(2.21)$ & $(0.28)$ & $(-0.82)$ & $(-0.40)$ \\
$\leq 3$ & 0.00054 & 0.00029 & -0.00042 & -0.00039 \\
& $(1.93)$ & $(1.30)$ & $(-0.10)$ & $(-0.15)$ \\
$\leq 4$ & 0.00063 & 0.00045 & 0.00233 & 0.00013 \\
& $(1.74)$ & $(1.68)$ & $(0.48)$ & $(0.04)$ \\
$\leq 5$ & 0.00073 & 0.00057 & 0.00180 & -0.00039 \\
& $(1.68)$ & $(1.80)$ & $(0.32)$ & $(-0.11)$ \\
$\leq 6$ & 0.00089 & 0.00065 & 0.00345 & -0.00037 \\
& $(1.83)$ & $(1.80)$ & $(0.57)$ & $(-0.09)$ \\
$\leq 7$ & 0.00106 & 0.00070 & 0.00412 & 0.00035 \\
& $(1.92)$ & $(1.69)$ & $(0.63)$ & $(0.08)$ \\
$\leq 8$ & 0.00125 & 0.00071 & 0.00298 & 0.00027 \\
& $(2.10)$ & $(1.51)$ & $(0.44)$ & $(0.05)$ \\
$\leq 9$ & 0.00141 & 0.00070 & 0.00147 & 0.00103 \\
& $(2.19)$ & $(1.33)$ & $(0.21)$ & $(0.19)$ \\
$\leq 10$ & 0.00163 & 0.00066 & 0.00045 & -0.00028 \\
& $(2.37)$ & $(1.13)$ & $(0.06)$ & $(-0.05)$ \\
\hline \hline$N$ & 3432 & 2949 & 522 & 824
\end{tabular}

Each cell of this table corresponds to a separate Probit regression. The marginal effects of county level unemployment rates on mortality are reported along with the t-statistic of the underlying coefficient estimate. Standard errors are clustered by individual. Each row corresponds to a separate dependent variable. Died $<=1$ means that the respondent died within one year of panel year; died $<=2$ means that the respondent died within two years of the panel year; etc. 
Table 3: Regression of Unemployment Rates on State and Year Fixed Effects

\begin{tabular}{llll} 
& $(1)$ & $(2)$ & $(3)$ \\
\hline \hline$R^{2}$ & 0.2753 & 0.3579 & 0.3368 \\
\hline \hline State Dummies & $\mathrm{X}$ & $\mathrm{X}$ & $\mathrm{X}$ \\
Year Dummies & & $\mathrm{X}$ & \\
State Time Trends & & & $\mathrm{X}$ \\
\hline \hline
\end{tabular}


Table 4: Robustness Checks for Men 60 and Under

\begin{tabular}{|c|c|c|c|c|c|}
\hline Died & $(1)$ & $(2)$ & $(3)$ & $(4)$ & $(5)$ \\
\hline$\leq 1$ & $\begin{array}{c}0.00026 \\
(1.88)\end{array}$ & $\begin{array}{c}0.00032 \\
(2.46)\end{array}$ & $\begin{array}{c}0.00010 \\
(1.40)\end{array}$ & $\begin{array}{c}0.00041 \\
(2.57)\end{array}$ & $\begin{array}{c}0.0006 \\
(3.04)\end{array}$ \\
\hline$\leq 2$ & $\begin{array}{c}0.00037 \\
(1.78)\end{array}$ & $\begin{array}{c}0.00042 \\
(1.94)\end{array}$ & $\begin{array}{c}0.00019 \\
(1.44)\end{array}$ & $\begin{array}{c}0.00057 \\
(2.32)\end{array}$ & $\begin{array}{c}0.00070 \\
(2.34)\end{array}$ \\
\hline$\leq 3$ & $\begin{array}{c}0.00053 \\
(1.70)\end{array}$ & $\begin{array}{c}0.00058 \\
(1.77)\end{array}$ & $\begin{array}{c}0.00040 \\
(1.42)\end{array}$ & $\begin{array}{c}0.00065 \\
(1.83)\end{array}$ & $\begin{array}{c}0.00087 \\
(1.96)\end{array}$ \\
\hline$\leq 4$ & $\begin{array}{c}0.00057 \\
(1.67)\end{array}$ & $\begin{array}{c}0.00063 \\
(1.78)\end{array}$ & $\begin{array}{c}0.00010 \\
(1.45)\end{array}$ & $\begin{array}{c}0.00057 \\
(1.69)\end{array}$ & $\begin{array}{c}0.00090 \\
(1.79)\end{array}$ \\
\hline$\leq 5$ & $\begin{array}{c}0.00075 \\
(1.82)\end{array}$ & $\begin{array}{c}0.00082 \\
(1.88)\end{array}$ & $\begin{array}{c}0.00056 \\
(1.75)\end{array}$ & $\begin{array}{c}0.00074 \\
(1.71)\end{array}$ & $\begin{array}{c}0.0011 \\
(1.82)\end{array}$ \\
\hline$\leq 6$ & $\begin{array}{c}0.00093 \\
(2.03)\end{array}$ & $\begin{array}{c}0.00098 \\
(2.00)\end{array}$ & $\begin{array}{c}0.00079 \\
(1.99)\end{array}$ & $\begin{array}{c}0.00088 \\
(1.75)\end{array}$ & $\begin{array}{c}0.00100 \\
(1.86)\end{array}$ \\
\hline$\leq 7$ & $\begin{array}{c}0.00098 \\
(1.94)\end{array}$ & $\begin{array}{c}0.00099 \\
(1.86)\end{array}$ & $\begin{array}{c}0.00046 \\
(1.74)\end{array}$ & $\begin{array}{c}0.00084 \\
(1.53)\end{array}$ & $\begin{array}{c}0.00104 \\
(1.74)\end{array}$ \\
\hline$\leq 8$ & $\begin{array}{c}0.00116 \\
(2.18)\end{array}$ & $\begin{array}{c}0.00111 \\
(1.98)\end{array}$ & $\begin{array}{c}0.00071 \\
(1.88)\end{array}$ & $\begin{array}{c}0.00092 \\
(1.58)\end{array}$ & $\begin{array}{c}0.00113 \\
(1.89)\end{array}$ \\
\hline$\leq 9$ & $\begin{array}{c}0.00134 \\
(2.28)\end{array}$ & $\begin{array}{c}0.00121 \\
(1.95)\end{array}$ & $\begin{array}{c}0.00100 \\
(1.86)\end{array}$ & $\begin{array}{c}0.00090 \\
(1.51)\end{array}$ & $\begin{array}{c}0.00120 \\
(1.91)\end{array}$ \\
\hline$\leq 10$ & $\begin{array}{c}0.00158 \\
(2.47) \\
\end{array}$ & $\begin{array}{c}0.00139 \\
(2.03) \\
\end{array}$ & $\begin{array}{c}0.00117 \\
(2.01) \\
\end{array}$ & $\begin{array}{c}0.00111 \\
(1.66) \\
\end{array}$ & $\begin{array}{c}0.00137 \\
(2.06) \\
\end{array}$ \\
\hline State Dummies & $\overline{\mathrm{X}}$ & $\overline{\mathrm{X}}$ & $\overline{\mathrm{X}}$ & $\overline{\mathrm{X}}$ & $\overline{\mathrm{X}}$ \\
\hline Year Dummies & & $\mathrm{X}$ & & $\mathrm{X}$ & $\mathrm{X}$ \\
\hline State Time Trends & & & $\mathrm{X}$ & & \\
\hline Industry Dummies & & & & $\mathrm{X}$ & \\
\hline Occupation Dummies & & & & & $\mathrm{X}$ \\
\hline$\overline{N N}$ & 3432 & 3432 & 3432 & $3 \overline{3432}$ & 3432 \\
\hline
\end{tabular}

Per Table 2. 
Table 5: Robustness Checks for Women 60 and Under

\begin{tabular}{|c|c|c|c|c|c|}
\hline Died & $(1)$ & $(2)$ & (3) & $(4)$ & (5) \\
\hline$\leq 1$ & $\begin{array}{c}0.00010 \\
(0.89)\end{array}$ & $\begin{array}{c}0.00010 \\
(1.23)\end{array}$ & $\begin{array}{c}0.00003 \\
(0.32)\end{array}$ & $\begin{array}{c}0.00020 \\
(1.16)\end{array}$ & $\begin{array}{c}0.00028 \\
(1.98)\end{array}$ \\
\hline$\leq 2$ & $\begin{array}{c}0.00002 \\
(0.09)\end{array}$ & $\begin{array}{c}0.00006 \\
(0.35)\end{array}$ & $\begin{array}{c}-0.00007 \\
(-0.46)\end{array}$ & $\begin{array}{c}0.00003 \\
(0.10)\end{array}$ & $\begin{array}{c}0.00016 \\
(0.46)\end{array}$ \\
\hline$\leq 3$ & $\begin{array}{c}0.00034 \\
(1.33)\end{array}$ & $\begin{array}{c}0.00036 \\
(1.33)\end{array}$ & $\begin{array}{c}0.00004 \\
(0.39)\end{array}$ & $\begin{array}{c}0.00045 \\
(1.15)\end{array}$ & $\begin{array}{c}0.00072 \\
(1.43)\end{array}$ \\
\hline$\leq 4$ & $\begin{array}{c}0.00057 \\
(1.78)\end{array}$ & $\begin{array}{c}0.00052 \\
(1.55)\end{array}$ & $\begin{array}{c}0.00022 \\
(0.79)\end{array}$ & $\begin{array}{c}0.00066 \\
(1.37)\end{array}$ & $\begin{array}{c}0.00086 \\
(1.53)\end{array}$ \\
\hline$\leq 5$ & $\begin{array}{c}0.00073 \\
(1.85)\end{array}$ & $\begin{array}{c}0.00060 \\
(1.44)\end{array}$ & $\begin{array}{c}0.00030 \\
(0.83)\end{array}$ & $\begin{array}{c}0.00075 \\
(1.27)\end{array}$ & $\begin{array}{c}0.00090 \\
(1.34)\end{array}$ \\
\hline$\leq 6$ & $\begin{array}{c}0.00067 \\
(1.82)\end{array}$ & $\begin{array}{c}0.00053 \\
(1.33)\end{array}$ & $\begin{array}{c}0.00001 \\
(0.78)\end{array}$ & $\begin{array}{c}0.00066 \\
(1.13)\end{array}$ & $\begin{array}{c}0.00074 \\
(1.22)\end{array}$ \\
\hline$\leq 7$ & $\begin{array}{c}0.00067 \\
(1.64)\end{array}$ & $\begin{array}{c}0.00048 \\
(1.08)\end{array}$ & $\begin{array}{c}0.00021 \\
(0.66)\end{array}$ & $\begin{array}{c}0.00054 \\
(0.89)\end{array}$ & $\begin{array}{c}0.00060 \\
(0.91)\end{array}$ \\
\hline$\leq 8$ & $\begin{array}{c}0.00063 \\
(1.36)\end{array}$ & $\begin{array}{c}0.00039 \\
(0.76)\end{array}$ & $\begin{array}{c}0.00019 \\
(0.44)\end{array}$ & $\begin{array}{c}0.00041 \\
(0.69)\end{array}$ & $\begin{array}{c}0.00040 \\
(0.59)\end{array}$ \\
\hline$\leq 9$ & $\begin{array}{c}0.00060 \\
(1.12)\end{array}$ & $\begin{array}{c}0.00038 \\
(0.66)\end{array}$ & $\begin{array}{c}0.00010 \\
(0.27)\end{array}$ & $\begin{array}{c}0.00038 \\
(0.58)\end{array}$ & $\begin{array}{c}0.00032 \\
(0.44)\end{array}$ \\
\hline$\leq 10$ & $\begin{array}{c}0.00053 \\
(0.88) \\
\end{array}$ & $\begin{array}{c}0.00039 \\
(0.59) \\
\end{array}$ & $\begin{array}{c}0.00003 \\
(0.06) \\
\end{array}$ & $\begin{array}{c}0.00040 \\
(0.54) \\
\end{array}$ & $\begin{array}{c}0.00026 \\
(0.32) \\
\end{array}$ \\
\hline "State Dummies & $\overline{\bar{X}}$ & $\overline{\mathrm{X}}$ & $\overline{\bar{X}}$ & $\overline{\mathrm{X}}$ & $\overline{\mathrm{X}}$ \\
\hline Year Dummies & & $\mathrm{X}$ & & $\mathrm{X}$ & $\mathrm{X}$ \\
\hline State Time Trends & & & $\mathrm{X}$ & & \\
\hline Industry Dummies & & & & $\mathrm{X}$ & \\
\hline Occupation Dummies & & & & & $\mathrm{X}$ \\
\hline 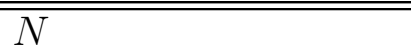 & 2949 & 2949 & 2949 & 2949 & 2949 \\
\hline
\end{tabular}

Per Table 2. 
Table 6: Mortality: Neoplasm

\begin{tabular}{ccccc} 
Died & Men & Women & Men & Women \\
\hline \hline & 60 and Under & \multicolumn{2}{c}{ Over 60} \\
\hline \hline$\leq 1$ & 0.00001 & 0.00000 & -0.00147 & -0.00098 \\
& $(0.30)$ & $(0.12)$ & $(-1.21)$ & $(-1.26)$ \\
$\leq 2$ & 0.00002 & 0.00001 & -0.00181 & -0.00078 \\
& $(0.62)$ & $(0.11)$ & $(-1.10)$ & $(-0.71)$ \\
$\leq 3$ & 0.00005 & 0.00001 & -0.00170 & -0.00064 \\
& $(0.94)$ & $(0.94)$ & $(-0.78)$ & $(-0.46)$ \\
$\leq 4$ & 0.00010 & 0.00012 & -0.00145 & -0.00061 \\
& $(1.38)$ & $(1.01)$ & $(-0.56)$ & $(-0.37)$ \\
$\leq 5$ & 0.00012 & 0.00016 & -0.00167 & -0.00085 \\
& $(1.55)$ & $(1.13)$ & $(-0.51)$ & $(-0.45)$ \\
$\leq 6$ & 0.00019 & 0.00019 & -0.00147 & -0.00150 \\
& $(2.03)$ & $(1.06)$ & $(-0.39)$ & $(-0.71)$ \\
$\leq 7$ & 0.00023 & 0.00020 & -0.00133 & -0.00158 \\
& $(2.03)$ & $(0.95)$ & $(-0.33)$ & $(-0.69)$ \\
$\leq 8$ & 0.00025 & 0.00023 & -0.00106 & -0.00142 \\
& $(2.22)$ & $(0.94)$ & $(-0.25)$ & $(-0.56)$ \\
$\leq 9$ & 0.00029 & 0.00022 & -0.00204 & -0.00111 \\
& $(2.36)$ & $(0.80)$ & $(-0.46)$ & $(-0.40)$ \\
$\leq 10$ & 0.00036 & 0.00021 & -0.00271 & -0.00144 \\
& $(2.71)$ & $(0.65)$ & $(-0.58)$ & $(-0.49)$ \\
\hline \hline$N$ & 3432 & 2949 & 522 & 824
\end{tabular}

Per Table 2. 
Table 7: Mortality: Circulatory Disease

\begin{tabular}{|c|c|c|c|c|}
\hline Died & Men & Women & Men & Women \\
\hline & \multicolumn{2}{|c|}{ "60 and Under } & \multicolumn{2}{|c|}{ Over 60} \\
\hline$\leq 1$ & $\begin{array}{c}0.00010 \\
(2.19)\end{array}$ & $\begin{array}{c}0.00004 \\
(1.26)\end{array}$ & $\begin{array}{c}-0.00020 \\
(-0.14)\end{array}$ & $\begin{array}{c}-0.00132 \\
(-1.71)\end{array}$ \\
\hline$\leq 2$ & $\begin{array}{c}0.00020 \\
(2.09)\end{array}$ & $\begin{array}{c}0.00004 \\
(0.87)\end{array}$ & $\begin{array}{c}0.00085 \\
(0.38)\end{array}$ & $\begin{array}{c}-0.00150 \\
(-1.29)\end{array}$ \\
\hline$\leq 3$ & $\begin{array}{c}0.00028 \\
(1.92)\end{array}$ & $\begin{array}{c}0.00009 \\
(1.33)\end{array}$ & $\begin{array}{c}0.00317 \\
(1.03)\end{array}$ & $\begin{array}{c}-0.00212 \\
(-1.25)\end{array}$ \\
\hline$\leq 4$ & $\begin{array}{c}0.00030 \\
(1.60)\end{array}$ & $\begin{array}{c}0.00012 \\
(1.45)\end{array}$ & $\begin{array}{c}0.00454 \\
(1.23)\end{array}$ & $\begin{array}{c}-0.00193 \\
(-0.89)\end{array}$ \\
\hline$\leq 5$ & $\begin{array}{c}0.00036 \\
(1.62)\end{array}$ & $\begin{array}{c}0.00014 \\
(1.44)\end{array}$ & $\begin{array}{c}0.00446 \\
(1.06)\end{array}$ & $\begin{array}{c}-0.00185 \\
(-0.75)\end{array}$ \\
\hline$\leq 6$ & $\begin{array}{c}0.00040 \\
(1.56)\end{array}$ & $\begin{array}{c}0.00015 \\
(1.34)\end{array}$ & $\begin{array}{c}0.00499 \\
(1.09)\end{array}$ & $\begin{array}{c}-0.00147 \\
(-0.52)\end{array}$ \\
\hline$\leq 7$ & $\begin{array}{c}0.00049 \\
(1.73)\end{array}$ & $\begin{array}{c}0.00016 \\
(1.39)\end{array}$ & $\begin{array}{c}0.00611 \\
(1.24)\end{array}$ & $\begin{array}{c}-0.00112 \\
(-0.36)\end{array}$ \\
\hline$\leq 8$ & $\begin{array}{c}0.00061 \\
(1.90)\end{array}$ & $\begin{array}{c}0.00020 \\
(1.51)\end{array}$ & $\begin{array}{c}0.00611 \\
(1.16)\end{array}$ & $\begin{array}{c}-0.00119 \\
(-0.35)\end{array}$ \\
\hline$\leq 9$ & $\begin{array}{c}0.00074 \\
(2.09)\end{array}$ & $\begin{array}{c}0.00022 \\
(1.51)\end{array}$ & $\begin{array}{c}0.00640 \\
(1.14)\end{array}$ & $\begin{array}{c}-0.00097 \\
(-0.26)\end{array}$ \\
\hline$\leq 10$ & $\begin{array}{c}0.00083 \\
(2.15) \\
\end{array}$ & $\begin{array}{c}0.00024 \\
(1.56) \\
\end{array}$ & $\begin{array}{c}0.00650 \\
(1.12) \\
\end{array}$ & $\begin{array}{c}-0.00095 \\
(-0.24) \\
\end{array}$ \\
\hline$\overline{N N}$ & 3432 & $\overline{2949}$ & $\overline{522}$ & 824 \\
\hline
\end{tabular}

Per Table 2. 